\title{
Dynamic Stability Enhancement of Power Transmission System using Artificial Neural Network Controlled Static Var Compensator
}

\author{
Amit Garg \\ Assistant Engineer, \\ Uttar Haryana Bijli Vitran Nigam, \\ Haryana, India.
}

\author{
Sanjai Kumar Agarwal \\ Professor \& HOD / EEE, \\ YMCA University of S\&T, \\ Faridabad, Haryana, India.
}

\begin{abstract}
Voltage level of the system changes at the time of fault and the drop in the load voltage leads to an increased demand for the reactive power that, if not met by the power system leads to a further decline in the bus voltage. This decline eventually leads to a progressive rapid decline of voltage at that location, which may have a cascading effect on neighboring regions that causes voltage collapse.In this paper, In order to maintain system stability after faults, the transmission line is shunt compensated at its center by a 200-Mvar Static Var Compenstor (SVC) in Matlab/Simulink. SVC are used to maintain the voltage with in the limits. SVC will either supply the reactive power or extract the reactive power. An Artificial Neural Network (ANN) is also developed with a systematic step-by-step procedure which optimizes a criterion commonly known as the learning rule. The input/output training data is fundamental for these networks as it conveys the information which is necessary to discover the optimal operating point. It is shown that trained Neural Network developed has excellent capabilities of forecasting which can be very useful in research.
\end{abstract}

\section{Keywords}

Artificial Neural Network (ANN), Dynamic Performance, FACTs,Matlab/Simulink, Transient Stability.

\section{INTRODUCTION}

Today's changing electric power systems create a growing need for flexibility, reliability, fast response and accuracy in the fields of electric power generation, transmission, distribution and consumption. Static Var Compensators (SVC) devices are used to improve voltage and reactive power conditions in AC systems. An additional task of SVC is to increase transmission capacity as result of power oscillation damping. The effectiveness of this controller depends on its optimal location and proper signal selection in the power system network[9]. Flexible AC Transmission System (FACTS) is a technology based solution to help the utility industry deal with changes in the power delivery business. A major thrust of FACTS technology is the development of power electric based systems that provide dynamic control of the power transfer parameters transmission voltage, line impedance and phase angle[3]. Static Var Compensator (SVC) provides fast acting dynamic reactive compensation for voltage support during contingency events which would otherwise depress the voltage for a significant length of time[10]. The flexible AC transmission system (FACTS) controllers can play an important role in the power system security enhancement. However, due to high capital investment, it is necessary to locate these controllers optimally in the power system. FACTS devices can regulate the active and reactive power control as well as adaptive to voltage-magnitude control simultaneously because of their flexibility and fast control characteristics. An Artificial Neural Network is a system based on the operation of biological neural networks, in other words, is an emulation of biological neural system. As its biological predecessor, an artificial neural network is an adaptive system. By adaptive, it means that each parameter is changed during its operation and it is deployed for solving the problem in matter. This is called the training phase.

\section{SVC V-I CHARACTERISTICS}

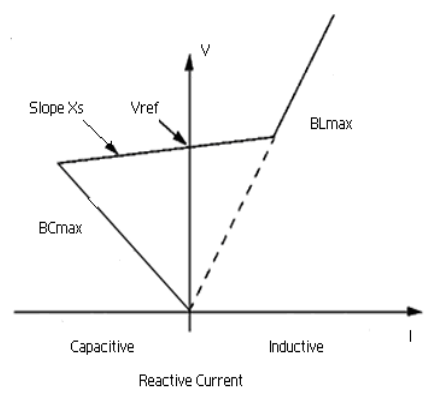

Fig 1: The V-I Characteristics of SVC

\section{SIMULATION}

\subsection{Transient Stability with SVC}

The SVC can be operated in two different modes:

- In voltage regulation mode.

- In var control mode (the SVC susceptance is kept constant).

When the SVC is operated in voltage regulation mode, it implements the V-I characteristic shown in Fig. 1.

\subsection{SVC Operating on 700 KM T.L}

A static var compensator (SVC) is used to regulate voltage on a sytem. When system voltage is low the SVC generates reactive power (SVC capacitive). When system voltage is high it absorbs reactive power (SVC inductive). SVC is rated as 200 Mvar 


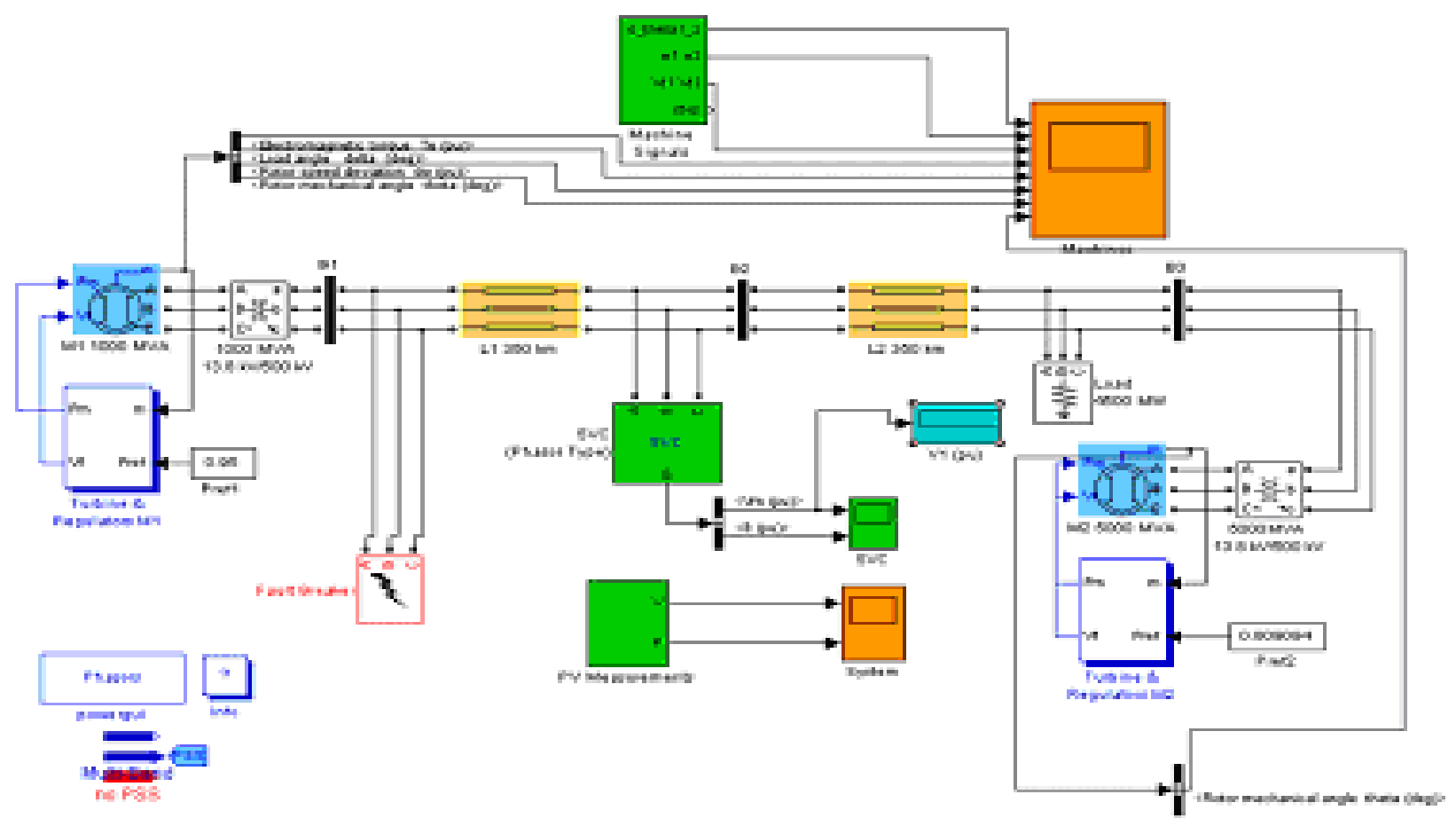

Fig 2 : SVC operating with T-G on $700 \mathrm{~km}$ Transmission Line in Matlab/Simulink

\section{ARTIFICIAL NEURAL NETWORK}

Artificial neural networks born after McCulloc and Pitts introduced a set of simplified neurons in 1943. These neurons were represented as models of biological networks into conceptual components for circuits that could perform computational tasks. The basic model of the artificial neuron is founded upon the functionality of the biological neuron. By definition, "Neurons are basic signaling units of the nervous system of a living being in which each neuron is a discrete cell whose several processes are from its cell body. One can differentiate between two basic types of networks, networks with feedback and those without it. In networks with feedback, the output values can be traced back to the input values. However there are networks wherein for every input vector laid on the network, an output vector is calculated and this can be read from the output neurons. There is no feedback. Hence only, a forward flow of information is present. Network having this structure are called as feed forward networks. There are various nets that come under the feed forward type of nets. A multilayer feed forward back propagation network with one layer of z-hidden units. The $\mathrm{Y}$ output unit has $\mathrm{W}_{\mathrm{ok}}$ bias and $\mathrm{Z}$ hidden unit has $\mathrm{V}_{\mathrm{ok}}$ as bias. It is found that both the output units and the hidden units have bias. The bias acts like weights on connection from units whose output is always 1 . This network has one input layer, one hidden layer and one output layer. There can be any number of hidden layers. The input layer is connected to the hidden layer and the hidden layer is connected to the output layer by means of interconnection weights. The bias is provided for both the hidden and the output layer, to act upon the net input to be calculated.

\section{TRAINING ALGORITHM}

The training algorithm of back propagation involves four stages, viz.

1. Initialization of Weights

2. Feed Forward

3. Back Propagation of errors

4. Updation of the weights and the biases.

During first stage which is the initialization of weights, some small random values are assigned. During feed forward stage each input unit $\left(\mathrm{X}_{\mathrm{i}}\right)$ receives an input signal and transmits this signal to each of the hidden units $\mathrm{Z} 1 \ldots \ldots \ldots . \mathrm{Zp}$. Each hidden unit then calculates the activation function and sends its signal $\mathrm{Zj}$ to each output unit. The output unit calculates the activation function to form the response of the net for the given input pattern. During back propagation of errors, each output unit compares its computed activation $y_{k}$ with its target value $t_{k}$ to determine the associated error for that pattern with that unit. Based on the error, the factor $\delta_{\mathrm{k}}$ is computed and is used to distribute the error at output unit $y_{k}$ back to all units in the previous layer. Similarly factor $\delta_{\mathrm{j}}$ is computed for each hidden unit $\mathrm{z}_{\mathrm{j}}$.During final stage, the weight and biases are updated using the $\delta$ factor and the activation .

$\mathrm{x}$ : input training vector

$\mathrm{x}:\left(\mathrm{x}_{1}, \ldots \ldots \ldots \mathrm{x}_{\mathrm{i}}, \ldots, \mathrm{x}_{\mathrm{n}}\right)$

t: Output target vector

$\mathrm{t}:\left(\mathrm{t}_{1}, \ldots \ldots \ldots . . \mathrm{t}_{\mathrm{i}}, \ldots, \mathrm{t}_{\mathrm{n}}\right)$ 
$\delta_{\mathrm{k}}=$ error at output unit $\mathrm{y}_{\mathrm{k}}$

$\delta_{\mathrm{j}}=$ error at hidden unit $\mathrm{zj}$

$\dot{\alpha}=$ learning rate

$\mathrm{V}_{\mathrm{oj}}=$ bias on hidden unit $\mathrm{j}$

$\mathrm{zj}=$ hidden unit $\mathrm{j}$

$\mathrm{w}_{\mathrm{ok}}=$ bias on output unit $\mathrm{k}$

$\mathrm{y}_{\mathrm{k}}=$ output unit $\mathrm{k}$

The training algorithm used in the back propagation network is as follows. The algorithm is given with the various phases:

\subsection{Initialization of Weights}

Step 1: Initialize weight to small random values.

Step 2: While stopping condition is false, do Steps 3-10.

Step 3: For each training pair do steps 4-9.

\subsection{Feed Forward}

Step 4: Each input unit receives the input signal $x_{i}$ and transmits this signals to all units in the layer above i.e hidden units

Step 5: Each hidden unit $\left(z_{j}, j=1, \ldots \ldots, p\right)$ sums its weighted input signals.

$\mathrm{Z}_{\text {-inj }}=\mathrm{v}_{\mathrm{oj}}+\Sigma \mathrm{x}_{\mathrm{i}} \mathrm{v}_{\mathrm{ij}}$

applying activation function

$\mathrm{Z}_{\mathrm{j}}=\mathrm{f}\left(\mathrm{z}_{\text {inj }}\right)$

and sends this signal to all units in the layer above i.e. output units.

Step 6: Each output unit $\left(\mathrm{y}_{\mathrm{k}}\right)$ sums its weighted input signals.

$\mathrm{y}_{\text {-ink }}=\mathrm{w}_{\mathrm{ok}}+\Sigma \mathrm{zjw}_{\mathrm{jk}}$

and applies its activation function to calculate the output signals.

$\mathrm{Y}_{\mathrm{k}}=\mathrm{f}\left(\mathrm{y}{ }^{-}{ }_{\mathrm{ink}}\right)$

\subsection{Back Propagation of Errors}

Step 7: Each output unit receives a target pattern corresponding to an input pattern, error information term is calculated as

$\delta_{\mathrm{k}}=\left(\mathrm{t}_{\mathrm{k}}-\mathrm{y}_{\mathrm{k}}\right) \mathrm{f}\left(\mathrm{y}-{ }_{\text {ink }}\right)$

Step 8: Each hidden unit (zj) sums its delta inputs from units in the layer above

$\delta_{\text {-inj }}=\Sigma \delta j \mathrm{w}_{\mathrm{jk}}$
The error information term is calculated as

$\delta_{\mathrm{j}}=\delta_{\text {-inj }} \mathrm{f}(\mathrm{z}$-inj $)$

\subsection{Updation of Weight and Biases}

Step 9: Each output unit (yk) updates its bias and weights $(\mathrm{j}=0, \ldots \ldots, \mathrm{p})$

The weight correction term is given by

$\Delta \mathrm{W}_{\mathrm{jk}}=\dot{\alpha} \delta_{\mathrm{k}} \mathrm{zj}$

and the bias correction term is given by

$\Delta \mathrm{W}_{\mathrm{ok}}=\alpha \dot{\alpha} \delta_{\mathrm{k}}$

Therefore $\mathrm{W}_{\mathrm{jk}}($ new $)=\mathrm{W}_{\mathrm{jk}}($ old $)+\Delta \mathrm{W}_{\mathrm{jk}}, \quad \mathrm{W}_{\mathrm{ok}}($ new $)=\mathrm{W}_{\mathrm{ok}}$ (old) $+\Delta \mathrm{W}_{\mathrm{ok}}$

Each hidden unit $(\mathrm{zj}, \mathrm{j}=1, \ldots \ldots . \mathrm{p})$ updates its bias and weights $(\mathrm{i}=0, \ldots . . \mathrm{n})$

The weight correction term

$\Delta \mathrm{V}_{\mathrm{ij}}=\alpha \delta_{\mathrm{j}} \mathrm{xi}$

The bias correction term

$\Delta \mathrm{V}_{\mathrm{oj}}=\alpha \delta_{\mathrm{j}}$

Therefore, $\mathrm{V}_{\mathrm{ij}}($ new $)=\mathrm{V}_{\mathrm{ij}}($ old $)+\Delta \mathrm{V}_{\mathrm{ij}}, \quad \mathrm{V}_{\mathrm{oj}}($ new $)=\mathrm{V}_{\mathrm{oj}}($ old $)+$ $\Delta \mathrm{V}_{\mathrm{oj}}$

Step 10: Test the stopping condition.

The stopping condition may be the minimization of the errors, number of epochs etc.

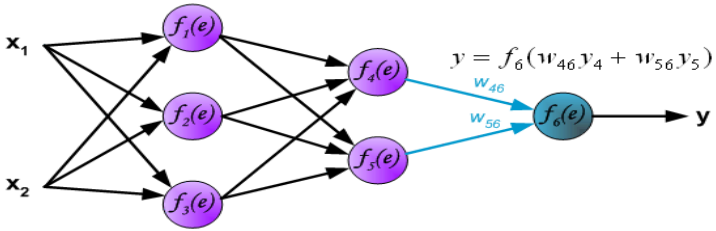

Fig 3: Feed Forward Networks

Fig 4: Back Propagation of Errors 


\section{SIMULATION RESULTS AND DISCUSSIONS}

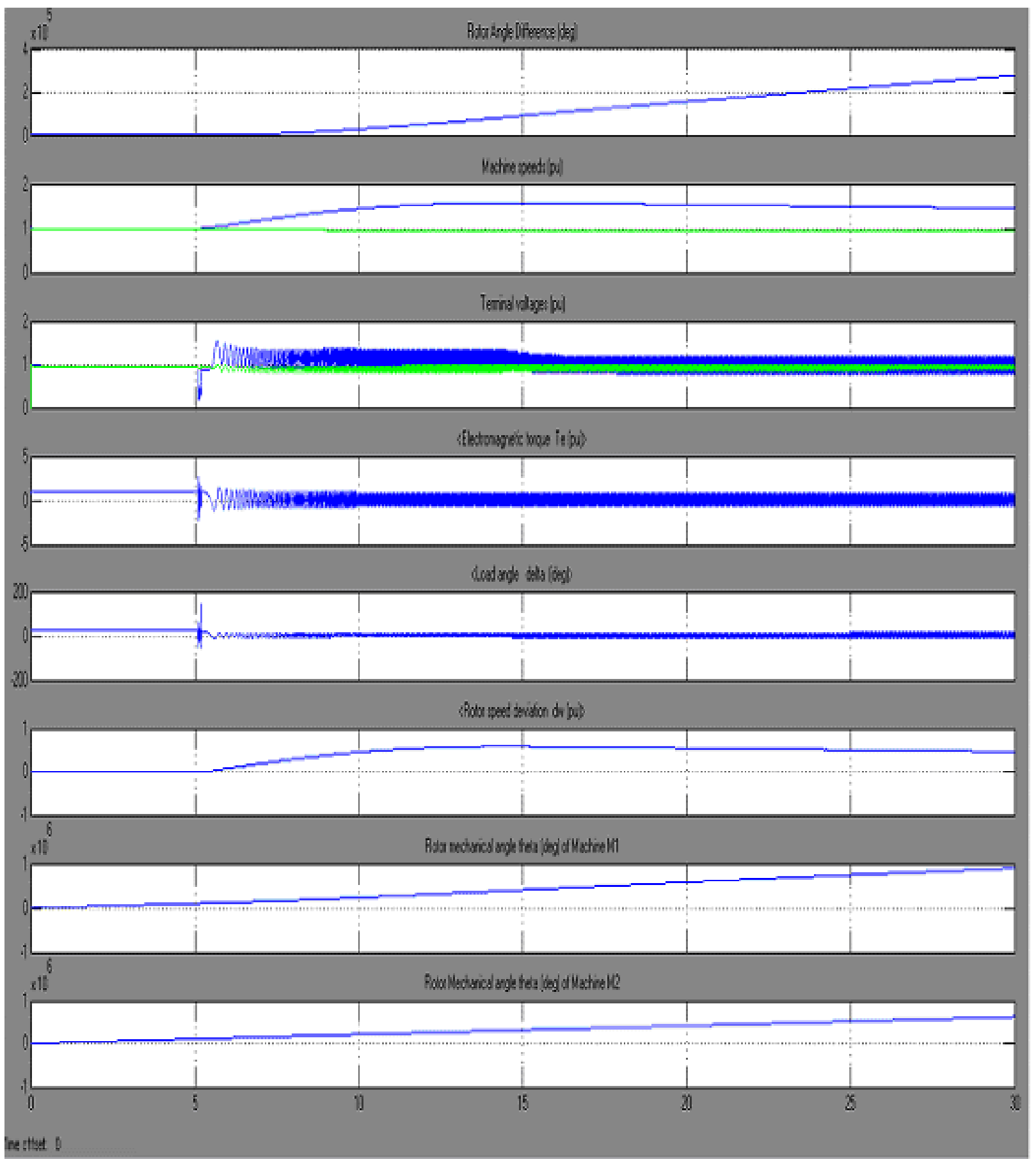

Fig 5: Signals Observed on 'Machines' Scope Without SVC

Now through SVC dialog box SVC is set to operate in 'Voltage Regulation' mode with Bref $=0$. This is equivalent to putting the SVC in service. 


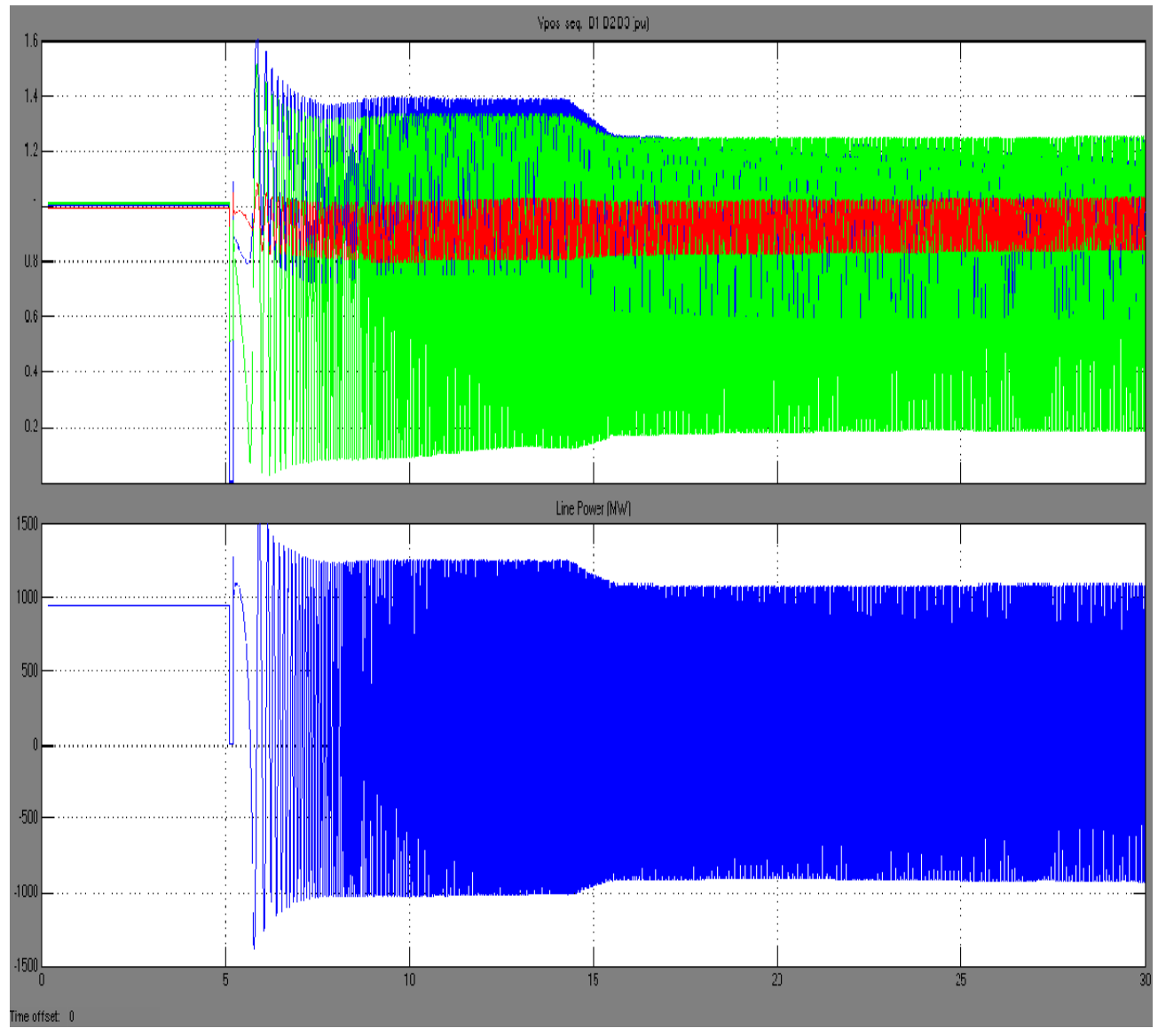

Fig 6: Signals Observed on 'System' Scope Without SVC

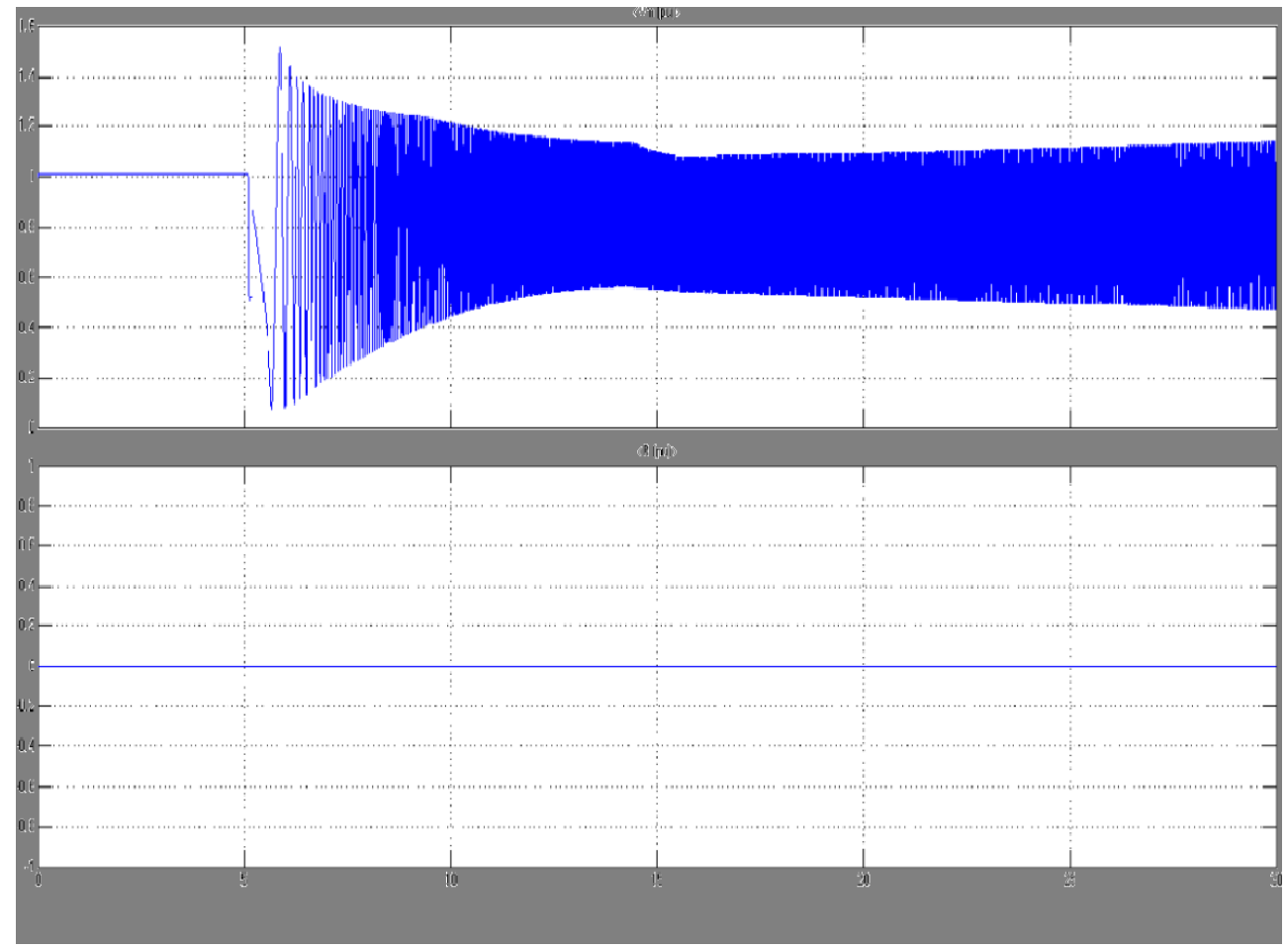

Fig 7: Signals Observed on 'SVC' Scope Without SVC 
Now through SVC dialog box SVC is set to operate in 'Voltage Regulation' mode with Bref $=0$. This is equivalent to putting the SVC in service.

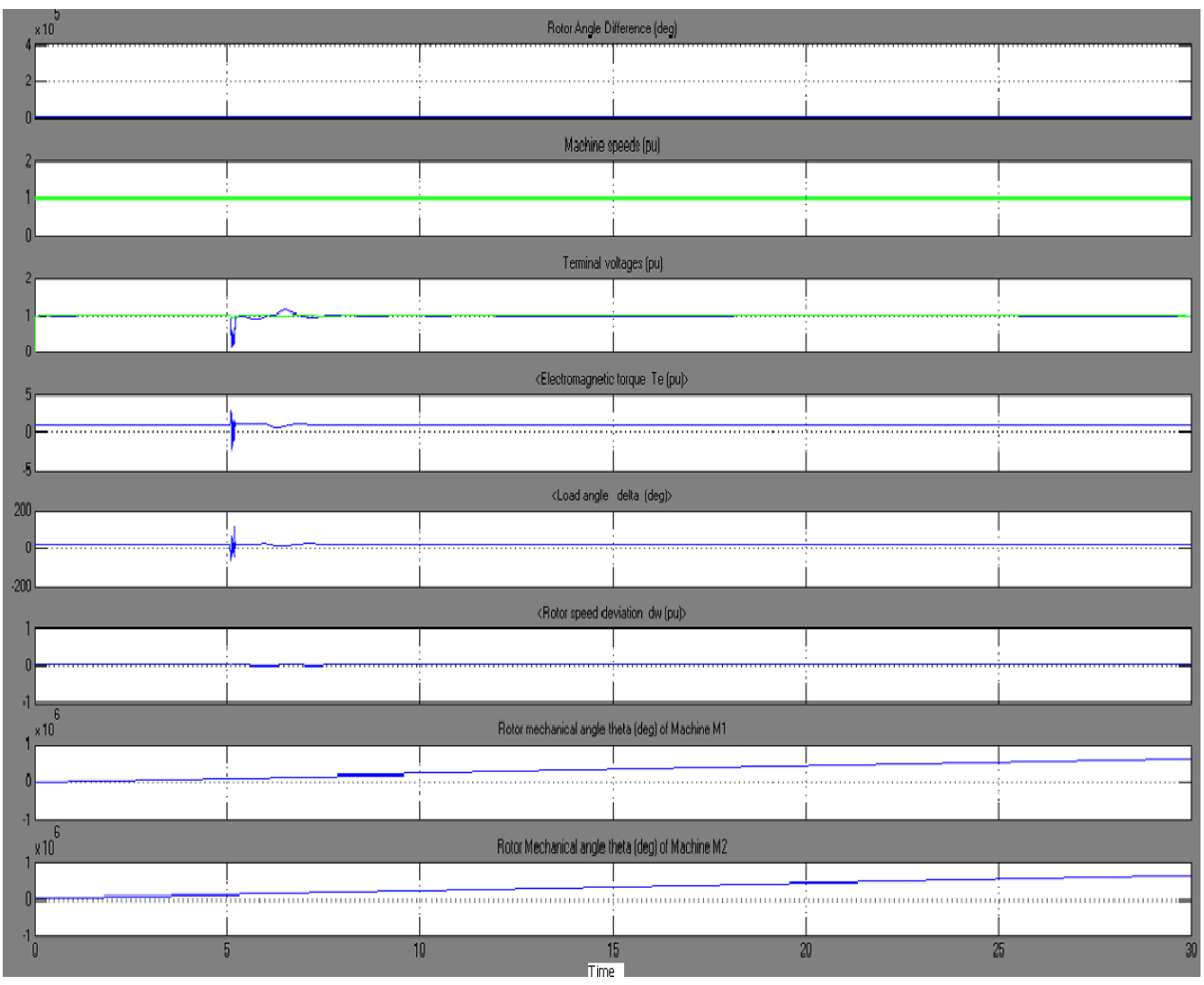

Fig 8: Signals Observed on 'Machines' Scope With SVC

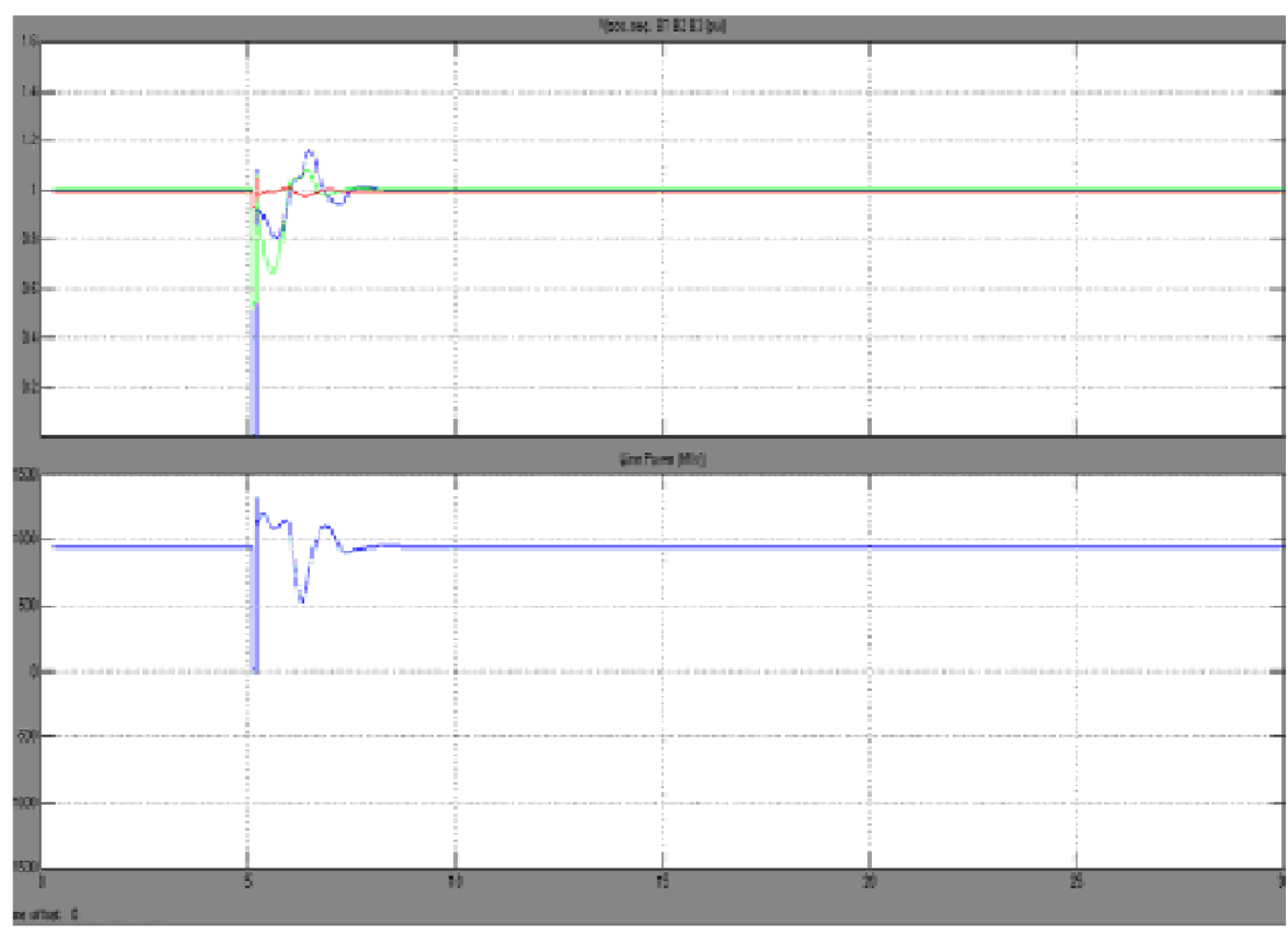

Fig 9: Signals Observed on 'System' Scope With SVC 


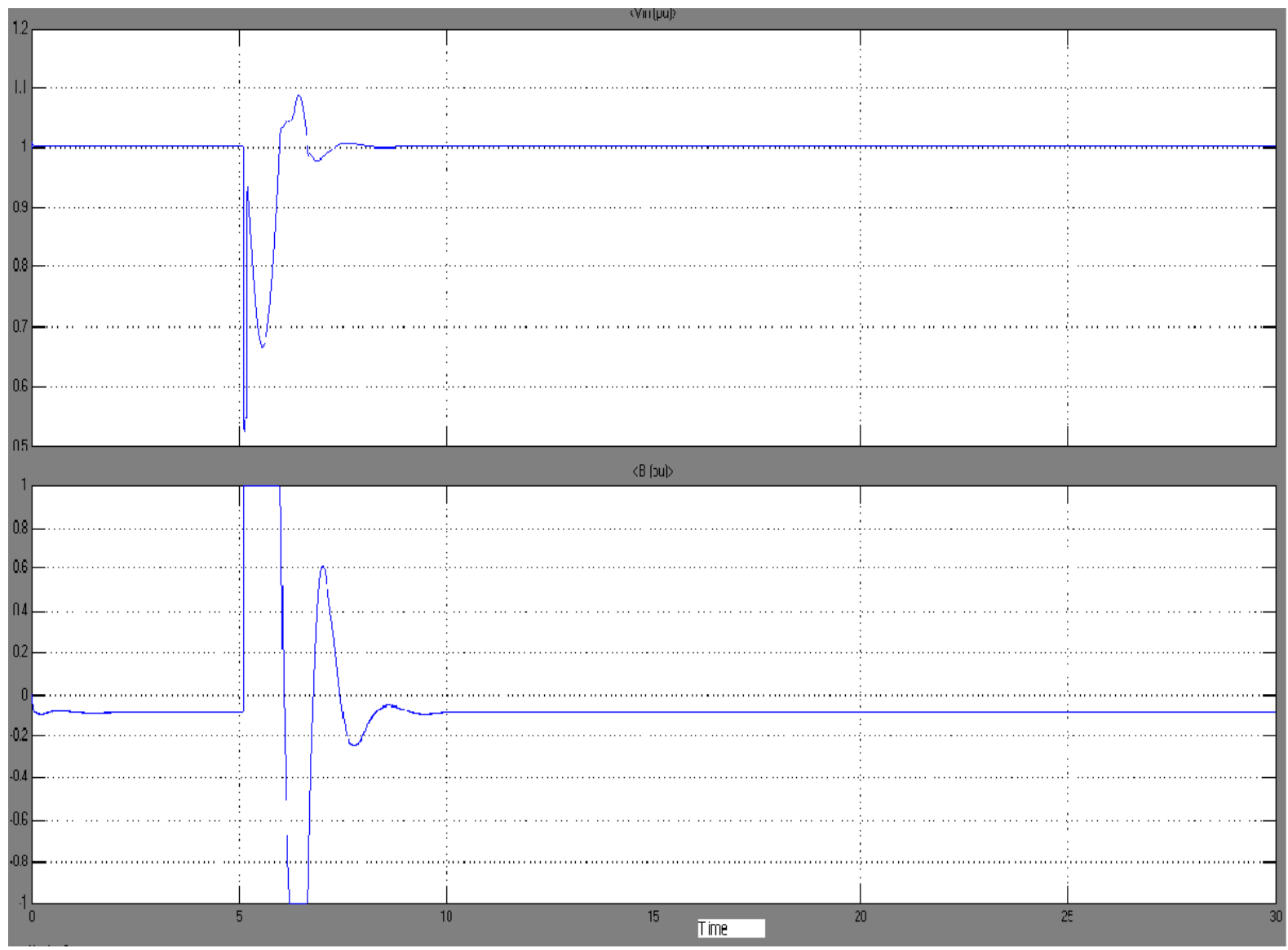

Fig 10: Signals Observed on 'SVC' Scope With SVC

Blue colour block shown in simulation is Display Block which updates its display of the values of Voltage V1(p.u). If the values of L1 and L2 and Resistive Load are varied the values of V1(p.u) also got varied and the corresponding values of $\mathrm{V} 1$ (p.u) is shown by the display box. Value of V1(p.u) at $6^{\text {th }}$ second is noted to train the feed-forward neural network

Table 1. Values of V1(p.u) at different values of L1, L2 and Resistive Load

\begin{tabular}{|c|c|c|c|}
\hline $\begin{array}{l}\text { Length of Tramomissian } \\
\text { Line (L 1) }\end{array}$ & $\begin{array}{l}\text { Length of } \\
\text { Tramsmission Linue } \\
\text { (I2) }\end{array}$ & $\begin{array}{l}\text { Resistive Load } \\
\text { (urw) }\end{array}$ & $\mathrm{V} 1(\mathrm{p}, \mathrm{y})$ \\
\hline 600 & 100 & 3500 & 1.14 \\
\hline 650 & 50 & 4000 & 1.08 \\
\hline 500 & 200 & 3500 & 1.17 \\
\hline 550 & 150 & 3800 & 1.14 \\
\hline 450 & 250 & 4000 & 1.15 \\
\hline 400 & 300 & 3000 & 1.22 \\
\hline 300 & 400 & 3200 & 1.20 \\
\hline 200 & 500 & 4400 & 1.14 \\
\hline 150 & 550 & 3900 & 1.17 \\
\hline 100 & 600 & 3300 & 1.18 \\
\hline 600 & 100 & 4200 & 1.09 \\
\hline 600 & 100 & 3800 & 1.12 \\
\hline 650 & 50 & 3000 & 1.17 \\
\hline 650 & 50 & 3700 & 1.10 \\
\hline 500 & 200 & 4200 & 1.12 \\
\hline 500 & 200 & 3900 & 1.14 \\
\hline 550 & 150 & 4500 & 1.09 \\
\hline 450 & 250 & 3700 & 1.17 \\
\hline
\end{tabular}


Table 2. Values of V1(p.u) obtained through Matlab/Simulink and through Neural Network

\begin{tabular}{|c|c|c|c|c|c|}
\hline $\begin{array}{l}\text { Lencth of } \\
\text { Transmission } \\
\text { Line (L 1) KDu }\end{array}$ & $\begin{array}{l}\text { Length of } \\
\text { Tramsmission } \\
\text { Line (L2) KDM }\end{array}$ & $\begin{array}{l}\text { Resistive Losd } \\
\text { (wrW) }\end{array}$ & $\begin{array}{l}\text { Wloud at } 6^{1} \\
\text { second of } \\
\text { simolatian }\end{array}$ & $\begin{array}{l}\text { Wahue of VI } \\
\text { obtained } \\
\text { trrough } \mathrm{Fr} \\
\text { (p.u) }\end{array}$ & Frror (\%) \\
\hline 100 & 600 & 4100 & 1.16 & 1.166 & -.517 \\
\hline 50 & 650 & 3200 & 1.17 & 1.228 & -4.95 \\
\hline 100 & 600 & 4300 & 1.15 & 1.154 & -.347 \\
\hline 150 & 550 & 4100 & 1.16 & 1.160 & 0 \\
\hline 200 & 500 & 3750 & 1.17 & 1.176 & -.512 \\
\hline 250 & 450 & 3400 & 1.19 & 1.191 & -.084 \\
\hline 150 & 550 & 3100 & 1.19 & 1.222 & -2.68 \\
\hline 200 & 500 & 2500 & 1.23 & 1.253 & -1.86 \\
\hline 600 & 100 & 3100 & 1.18 & 1.169 & .932 \\
\hline 650 & 50 & 3300 & 1.14 & 1.152 & -1.05 \\
\hline 200 & 500 & 3900 & 1.17 & 1.166 & .341 \\
\hline 250 & 450 & 4100 & 1.16 & 1.148 & 1.03 \\
\hline 450 & 250 & 3000 & 1.22 & 1.192 & 2.29 \\
\hline 100 & 600 & 2100 & 1.23 & 1.289 & -4.79 \\
\hline 300 & 400 & 3150 & 1.21 & 1.201 & .743 \\
\hline 350 & 350 & 3650 & 1.18 & 1.164 & 1.35 \\
\hline 600 & 100 & 2700 & 1.20 & 1.194 & 0.5 \\
\hline 400 & 300 & 3600 & 1.18 & 1.161 & 1.61 \\
\hline 130 & 570 & 2100 & 1.24 & 1.285 & -3.62 \\
\hline
\end{tabular}

\section{CONCLUSION}

Hence it can be concluded that SVC will successfully control the dynamic performance of power system and will effectively regulate the system oscillatory disturbances and voltage regulation of the power system. Simulations carried out confirm that SVC could provide the fast acting voltage support necessary to prevent the possibility of voltage reduction and voltage collapse. This paper inspects actual positive sequence voltage in a system model with or without SVC. However it is well known that these FACTS controllers have the additional advantage of being able to control "fast" system oscillations due to their quick response. Hence by properly modeling these controllers in transient stability programs, it would be interesting to determine any other possible advantages of these controllers in voltage stability studies. The presented simulation results shows that SVC is capable to power system oscillation damping successfully. In this paper following signals i.e Rotor Angle difference (deg), Machine speeds(pu), Terminal Voltage(pu), Electromagnetic Torque(pu), Load Angle delta(deg), Rotor speed deviation dw(pu), Rotor mechanical angle(deg) theta of machine M1, Rotor mechanical angle(deg) theta of machine M2, Vpos. Seq.(pu), Line Power(MW), Vm(pu), B(pu) are observed on 'Machines', 'System' and 'SVC' scopes. The authors are currently working on developing appropriate models for other FACTS controllers, namely, STATCOM, SSSC, UPFC for transient and steady state stability analysis, to also analyze the advantages and disadvantages of these controllers in voltage stability studies. Value of voltage (V1) is varied by varying the values of the values of $\mathrm{L} 1$ and $\mathrm{L} 2$ and Resistive Load (MW) and then displayed at display block at $6^{\text {th }}$ second as shown in Table 1 . Using these values of voltage $\mathrm{V} 1 \mathrm{a}$ feed-forward network is trained. After the completion of training phase a Feed Forward Neural Network is developed which can forecast a value of voltage V1 at any value of L1, L2 and Resistive Load (MW). Table 2. shows the values of voltage V1 at different values of L1, L2 and Resistive Load (MW) obtained through simulink and through Neural Network also with the corresponding values of error. It is realized that a Feed Forward Neural Network has excellent capability of forecasting the values of voltage V1 which can be very useful for further research.

\section{REFERENCES}

[1] Nang Sabai, and Thida Win (2008) "Voltage control and dynamic performance of power transmission system using SVC" World Academy of Science, Engineering and Technology 42 Pp. 425-429

[2] P.Kundur, "Power system stability and control", Mc Graw-Hill, 1994

[3] D. Murali (October 2010),"Comparison of FACTS devices for power system stability enhancement" International Journal of Computer Applications (0975 - 8887) Volume 8- No.4, Pp. 30-35

[4] H. Yazdanpanahi ,"Application of FACTS devices in transmission expansion to overcome the problems related to delays".

[5] A.E. Hammad, "Analysis of power system stability enhancement by static var compensator", IEEE PWRS, vol 1, no 4, pp. 222-227.

[6] Christian Rehtanz April (2009), ,New types of FACTS devices for power system security and efficiency" Pp-16.

[7] Hadi Saadat, "Power system analysis", Mc Graw-Hill companies. Inc, 1999. 
[8] Edris Abdel, "Series Compensation Schemes Reducing the Potential of Sub synchronous Resonance, "IEEE Trans. On power systems, vol. 5 No. 1. Feb1990. Pp. 219-226

[9] Atef Aly El-Emary, "Effect of static VAR compensator upon synchronizing Torque coefficient." Electric Machines and Power Systems 25:371-386, 1977.

[10] A.R. Messina, O. Begovich M. "Analytical investigation of the use of static Var compensators to aid damping of inter area oscillations." Electric Power System Research 21(1999) 199-210.
[11] A.H.M.A. Rahim, M.F. Kandlawala, "Robust STATCOM voltage controller design using loopshaping technique." Electric Power System Research, vol. 60, Jan. 2004, 61-74.

[12] A.H.M.A., S.A. Al-Baiyat and H.M.Al-Maghrabi, "Robust damping controller design for static compensator," IEE Proceedings Generation Transmission Distribution 149, 4(2002), pp. 491-496. 